Check for updates

Cite this: Mater. Adv., 2021, 2, 3385

Received 9th January 2021 Accepted 25th March 2021

DOI: $10.1039 / \mathrm{d} 1 \mathrm{ma} 00017 \mathrm{a}$

rsc.li/materials-advances

\title{
Assessment of dihydropyrimidinone-based nanocomposites as multifunctional anti-cancer drug $\dagger$
}

\author{
Thangamani S. $\neq^{\mathrm{a}}$ Hema Priya Mahendran, $\ddagger^{\mathrm{bc}}$ Rama Ranjan Bhattacharjee, (D) d \\ Sankarganesh Jeyaraj*bc and Kallol Mohanta (D)*a
}

\begin{abstract}
Dihydropyrimidinones, which are known as Biginelli compounds, have been found to be tumor inhibitors in the last decade. Herein, novel carbon quantum dot-dihydropyrimidinone (CQD-DHPM) nanocomposites were prepared via a simple conjugation process by varying the ratio of DHPM to CQDs. This conjugation endowed fluorescence properties to the medicinal DHPM compound and offered multifunctionality. CQDDHPM nanocomposites were tested for their anti-cancer activity against the human non-small cell lung cancer A549 cell line. It was found that conjugating CQDs with DHPM improved its anti-cancer activity and reduced its cytotoxicity towards healthy cells. The fluorescence properties of composites also enabled them

to serve as bioimaging fluorophores.
\end{abstract}

\section{Introduction}

Efficiently processable dihydropyrimidinones (DHPMs) are well known for their strong pharmacological properties such as antioxidant, ${ }^{1}$ antimicrobial, ${ }^{2}$ antitumoral ${ }^{3}$ and inhibition to HIV-1, ${ }^{4}$ and lipoxygenase activity. ${ }^{5}$ They have also proven to demonstrate their ability against HepG2 and HeLa cell lines, ${ }^{6}$ human polyomavirus (HPyV), and Hsp90 C-terminal inhibitors. ${ }^{7}$ DHPM compounds specifically inhibit the Eg5 motor spindle protein and restrict the mitotic progression of cells, and hence can be used as anti-cancer drugs. ${ }^{8}$ Matos et al. reported that DHPM and its derivatives were tested on various cancer cell lines, including lung, breast, prostate, and colorectal cancer. $^{9}$

The half maximal inhibitory concentration $\left(\mathrm{IC}_{50}\right)$ is a measure of the potency of an inhibitor to inhibit certain biological functions; a lower $\mathrm{IC}_{50}$ value of a drug to inhibit tumor cellgrowth is recommended given that it will have less side-effects.

\footnotetext{
${ }^{a}$ PSG Institute of Advanced Studies, Coimbatore, Tamil Nadu, 641004, India. E-mail:kmohanta@gmail.com,kma@psgias.ac.in

${ }^{b}$ PSG Center for Molecular Medicine and Therapeutics, PSG Institute of Medical Sciences \& Research (Affiliated to the Tamil Nadu Dr MGR Medical University), Coimbatore, Tamil Nadu, 641004, India. E-mail: sankar.jeyaraj@gmail.com ${ }^{c}$ PSG Center for Genetics and Molecular Biology, Off Avinashi Road, Coimbatore 641004, India

${ }^{d}$ Amity Institute of Nanotechnology, Amity University, Kolkata, West Bengal, 700135, India

$\dagger$ Electronic supplementary information (ESI) available. See DOI: 10.1039/ d1ma00017a

\# The authors have equal contribution.
}

Ragab et al. reported that U251 (glioblastoma multiforme) and OVCAR-03 (ovarian cancer) were found to be more sensitive to DHPM derivatives, which affected cell growth at $\mathrm{IC}_{50}<$ $10 \mu \mathrm{g} \mathrm{mL}^{-1} \cdot{ }^{10}$ Non-small cell lung carcinoma (NSCLC) is a devastating cancer arising in lung epithelial cells. NSCLC accounts for about $85 \%$ of lung cancer. ${ }^{11}$ It usually grows and spreads slowly compared to small cell lung cancer and is considered as the most common lung carcinoma. ${ }^{12}$ This cancer remains aggressive with increasing incidence and poor survival rate despite current multimodal treatments. NSCLC was modeled on the A549 cell line, which is adenocarcinomic and composed of human alveolar basal epithelial cells. In a previous study, cytotoxicity against the A549 cell line was tested using compounds such as 2-(5-nitrofurfurylidene)-5-(aryl)-7(2,4-dichloro-5-fluorophenyl)-5 $H$-thiazolo[2,3-b]pyrimidin-3-ones, 2-(5-arylfurfurylidene)-5-(aryl)-(2,4-dichloro-5-fluorophenyl)$5 H$-thiazolo[2,3-b]pyrimidin-3-ones, and 4-aryl-6-(2,4-dichloro5-fluorophenyl)-3,4-dihydropyrimidin-2(1H)-thiones, which exhibited a minimum $\mathrm{IC}_{50}$ of $16.5 \mu \mathrm{M} .^{13}$

In modern drug innovation, including multifunctionality in a drug is carefully contemplated so that a single composition can address several purposes related to an ailment. One of the key aspects of multifunctional drugs is to track them inside body or in body fluids so that the dosage of the drug and the monitoring of drug to targets can also be optimized. Fluorescent tagging of a drug molecule enables real-time monitoring of the drug inside living systems. Fluorescence properties aid in determining drug-target interactions, drug-tubulin interfacing, and pharmaco-dynamic consequences. ${ }^{14}$ Thus, considering that DHPM compounds do not possess any fluorescence property, ${ }^{15}$ 
luminous hybrid DHPM composites for applications such as drug detection and bioimaging are limited. However, with the advent of nanomaterials, targeting ailing cells and tracking drugs have been getting simpler. Attaching/conjugating a fluorescent nanomaterial to a particular drug molecule to achieve fluorescence properties is a common practice in current research. ${ }^{16}$

CQDs are the newest class of carbon nanomaterials, which have various advantages such as simple and inexpensive synthesis, tunable properties, and modifiability. ${ }^{17}$ Furthermore, CQDs have dynamic fluorescence properties, high chemical stability, low cytotoxicity and biocompatibility. ${ }^{18,19}$ Their biocompatible features combined with their fluorescence properties enable them to efficiently serve as effective fluorophores for bioimaging and probes for drug delivery. ${ }^{20}$ Wang et al. reported that CQDs modified with zinc oxide and silica-based materials have biological applications due to their fluorescence properties. ${ }^{21}$ Prasad et al. demonstrated the significant anti-cancer property of CQDs made from small organic molecules against a breast cancer cell line. ${ }^{22}$ However, reports on the integration of CQDs with pharmacological molecules were rare until Qu et al. synthesized CQD-TPEA. ${ }^{23}$ This nanocomposite was prepared by attaching TPEA ( $\mathrm{N}$-(2-aminoethyl)$N, N, N$-tris(pyridin-2-ylmethyl)ethane-1,2-diamine) to water-soluble CQD particles. The TPEA-CQD composite showed low cytotoxicity and was used for intercellular sensing and bio-tagging of $\mathrm{Cu}^{2+} \cdot{ }^{23}$

The aim of this study was to prepare a hybrid fluorescent monastrol composite based on the combination of DHPM and CQD, i.e., CQD-DHPM, to evaluate its anti-cancer property in the A549 cell line and determine its bioimaging capability. The surface of CQDs contains suitable functional groups (polystyrene sulphonate) as a capping agent so that the optical properties of the CQDs and the therapeutic performance of DHPM can be retained in the new conjugation. The pharmacological agent, CQD-DHPM nanocomposite, developed in this study was evaluated to estimate its anti-cancer activity against the A549 cell line. Accordingly, we evaluated the effect of our novel CQD-DHPM nanocomposites at different ratios in combination and as individuals against the A549 cell line as a model for NSCLC. It was found that the nanocomposite increased the reactivity of the DHPM compound (without subgroup) and lowered its cytotoxicity towards healthy cells.

\section{Experimental section}

\section{Materials}

Benzyl alcohol, hydrogen peroxide, ethyl acetoacetate, urea and citric acid (CA) were purchased from LOBA Chemie and used as received without further purification. Jeffamine ${ }^{\circledR}$ was obtained as a gift sample from Huntsman India Ltd. Phosphotungstic acid (PTA) and poly(sodium 4-styrene sulfonate) (PSS) were purchased from Fluka and Sigma-Aldrich, respectively, and used as received. The standards and the reaction mixtures were spotted on TLC Silica Gel 60 F254 purchased from Merck Chemicals. Milli-Q water was used in all procedures.

Peripheral blood mononuclear cells (PBMCs) from healthy controls, human non-small cell lung cancer cells, and the A549 cell line for pharmacological tests were used with proper ethical guidelines from Institutional Human Ethics Committee, PSG Institute of Medical Sciences and Research, Coimbatore.

\section{Synthesis of dihydropyrimidinone and carbon quantum dots}

Dihydropyrimidinone was prepared by Biginelli reaction. Dihydropyrimidinone was synthesized according to the route described elsewhere. ${ }^{24}$ Carbon quantum dots were prepared according to our previous report. ${ }^{17}$ The detailed procedures for the synthesis of dihydropyrimidinone and CQDs are presented in the ESI. $\dagger$

\section{Preparation of CQD-DHPM nanocomposites}

The preparation of the CQD-DHPM nanocomposites with different proportions of CQD to DHPM was carried as follows: $10 \mathrm{mg}$ of CQDs in $10 \mathrm{~mL}$ of water was stirred to obtain a CQD dispersion, and 10, 20, 30 and $40 \mathrm{mg}$ of DHPM were completely dissolved in $10 \mathrm{~mL}$ ethanol each (for $1: 1,1: 2,1: 3$ and $1: 4$ ratio, respectively) and stirred continuously. Then the DHPM solution was added dropwise to the CQD solution with continuous stirring. The immediate sample of CQD-DHPM was taken for analysis. Samples were collected at regular intervals of $15 \mathrm{~min}$ up to $90 \mathrm{~min}$. The solution was initially characterized by fluorescence microscopy. The formation of the nanocomposites was confirmed by optical, compositional, thermal and morphological analysis.

\section{Characterization tools}

Ultraviolet-visible absorption (UV-vis) spectra were recorded using a Shimadzu UV-1800 spectrophotometer in the wavelength range of $200-800 \mathrm{~nm}$ in a $3 \mathrm{~mm}$ path-length cuvette with a concentration of $1 \mathrm{mg} \mathrm{mL}^{-1}$ in DI water for all the samples. Fourier Transformed infra-red absorption (FT-IR) spectra were recorded using a Shimadzu IR Affinity Series 1S in the range of 4500-600 $\mathrm{cm}^{-1}$ and nuclear magnetic resonance (NMR) spectra were recorded using a Bruker BioSpin GmbH. Thermogravimetric analysis measurements were carried out using a NETSCH STA 449F3 Jupiter thermal analyzer under a nitrogen atmosphere. Fluorescence emission and excitation spectra were recorded using a Shimadzu RF-5301PC spectrofluorophotometer with $1 \mathrm{mg} \mathrm{mL} \mathrm{mL}^{-1}$ concentration of sample in aqueous medium. The fluorescence microscopic studies were carried out using a Nikon Upright Microscope Eclipse Ni-U. The samples were analyzed under different excitation wavelengths in the blue (Ex: 330-380 nm), green (Ex: 450-490 nm) and red (Ex: 510-560 $\mathrm{nm}$ ) regions. High-resolution transmission electron microscopy (HR-TEM) analysis was performed for nanoparticle measurement using a JEOL JEM 2100.

\section{Cell culture}

A549 cells were grown in complete DMEM, at an optimum temperature of $37{ }^{\circ} \mathrm{C}$ with $5 \% \mathrm{CO}_{2}$. The culture medium was supplemented with $10 \%$ fetal bovine serum (FBS), 1\% L-glutamine, and 1\% antibiotic-antimycotic solution. The cells were grown aseptically in tissue culture flasks ( $\left.T 25 \mathrm{~cm}^{2}\right)$. Fresh PBMCs were also included to determine whether 
the compounds displayed any toxicity towards normal cells. The PBMCs were isolated by density gradient centrifugation using the Ficoll-Paque overlay method and grown aseptically in tissue culture flasks ( $\mathrm{T} 75^{2}$ ) using medium comprised of RPMI-1640, 10\% heat-inactivated filtered fetal bovine serum (FBS), and $1 \%$ streptomycin and penicillin solution. The cultures were incubated in a humidified $5 \% \mathrm{CO}_{2}$ incubator at $37{ }^{\circ} \mathrm{C}$.

\section{Cytotoxicity assay}

The investigation of the in vitro cytotoxicity of the CQD-DHPM nanocomposites using the MTT assay was carried out in 96-well, flat bottomed microtiter plates. A volume of $200 \mu \mathrm{L}$ complete culture medium containing $5 \times 10^{3}$ cells was seeded in each well on the first day of the experiment and incubated for $24 \mathrm{~h}$ for the cells to attach to the wells. The following day, the old medium was replaced with fresh medium containing different concentrations $(\mu \mathrm{M})(25,50,100,200,300,400$ and $500)$ of the drug and incubated at an optimum temperature of $37{ }^{\circ} \mathrm{C}$ with $5 \% \mathrm{CO}_{2}$ for $24 \mathrm{~h}$. To determine the cytotoxicity, 10-15 $\mu \mathrm{L}$ of $5 \mathrm{mg} \mathrm{mL}^{-1}$ 3-(4,5-dimethylthiazol-2-yl)-2,5diphenylterazolium bromide (MTT) was added followed by incubating the plates for $3 \mathrm{~h}$ at $37{ }^{\circ} \mathrm{C}$ in the dark. After $3 \mathrm{~h}$, the medium was aspirated and $100 \mu \mathrm{L}$ of DMSO was added to each well and the absorbance was read at $590 \mathrm{~nm}$ using a Varioskan Flash multimode microtiter plate reader. The $\mathrm{IC}_{50}$ values were determined by non-linear regression analysis. To determine the in vitro cytotoxicity of DHPM on freshly isolated PBMCs from healthy blood donors, around $1 \times 10^{5}$ cells were seeded per well and incubated with different concentrations $(\mu \mathrm{M})(25,50,100,200,300,400$ and 500$)$ of the compound at $37{ }^{\circ} \mathrm{C}$ with $5 \% \mathrm{CO}_{2}$ for $72 \mathrm{~h}$ to determine the maximum cytotoxic effect. After incubation, the MTT assay was performed, and the absorbance was read at $590 \mathrm{~nm}$. The mean percentage of the post-treatment viable cells was calculated using the following formulae.

$$
\% \text { Cell viability }=\frac{\text { Absorbance of treated cells } \times 100}{\text { Absorbance of untreated cells }}
$$

$$
\% \text { Cytotoxicity }=100-\% \text { Cell viability }
$$

\section{Fluorescence microscopy}

Cells from flasks were harvested by trypsinization and $0.5 \times 10^{4}$ cells were seeded on a sterile 8 -well chamber slide overnight at $37{ }^{\circ} \mathrm{C}$ for fluorescence microscopy. The next day, the cells were treated with drug compounds (CQDs and CQD-DHPM nanocomposites) at the $\mathrm{IC}_{50}$ concentration and incubated at $37{ }^{\circ} \mathrm{C}$ for $24 \mathrm{~h}$. After incubation, the medium was aspirated, and the attached cells were washed twice with PBS. The chamber walls were then carefully removed with forceps and the cells were then covered with a cover slip and directly viewed under a fluorescent microscope (using UV light). Images were taken after mounting the slide with a cover slip and mounting medium.

\section{Results and discussion}

In a previous study, the dihydropyrimidinone molecule was evaluated for its antitumor activity against the A549 cell line and its half maximal inhibitory concentration, i.e., $\mathrm{IC}_{50}$ value, was determined to be $202.6 \mu \mathrm{M}^{24}$ Although DHPM has commendable biological activities, it lacks fluorescence properties, which restricts its application in bioimaging. Fluorophores for the DHPM molecule are not readily available or existing materials are unsuitable as fluorophores with the DHPM molecule given that they may alter the pharmacological activity of this drug molecule. To date, mostly coumarin-based materials have been used as efficient fluorophores due to their benign nature, although coumarin has its own limitations such as photo bleaching and photo damaging of the embodying tissues due to its low excitation and emission wavelengths. ${ }^{25}$ The recently developed carbon quantum dots (CQDs) possess interesting fluorescence properties. They have a wide range of excitation-dependent emissions and are also non-cytotoxic. ${ }^{26}$ Carbon quantum dots are relatively inactive and can be functionalized according to the requirements. These advantages make carbon quantum dots promising alternatives to coumarin as a fluorophore.

The CQD-DHPM nanocomposite was analyzed by highresolution transmission electron microscopy (HR-TEM) to study its size distribution and lattice properties. Fig. $1 \mathrm{a}$ and $\mathrm{b}$ show CQDs and CQD-DHPM (ratio 1:2) and their magnified version, respectively. It can be seen from Fig. 1a that the individual CQD particles have mostly oblong shapes with a size of $5 \pm 2 \mathrm{~nm}$. Conversely, the CQD-DHPM particles were observed as a cloudy agglomeration of organic molecules with sparse tints of firm structures, as shown in Fig. 1b. Due to the presence of strong interatomic interactions, the molecules did not show a defined structure. The deep black points within this cloudy formation could be the CQDs/CQD clusters, which are attached with the DHPM molecules. The size of these formations is about $200 \mathrm{~nm}$, which is much bigger than the single CQDs $(\sim 5 \mathrm{~nm})$ and reveals the structure of the conjugate. The atomic force microscopy morphology study of CQD-DHPM (ratio 1:2) also supports the transmission electron microscopy observations. Fig. S1a and b (ESI $\dagger$ ) show the topographies of CQD-DHPM particles scattered on a glass substrate at different magnifications. The AFM images show the presence of $\sim 0.2 \mu \mathrm{m}$ particles, which represent the CQD-DHPM particle and >10 nm CQDs can be observed in the background.

The thermogravimetric analysis (TGA) of the pure DHPM and CQD-DHPM (1:2 ratio) in a nitrogen atmosphere was carried out to confirm the conjugation of the DHPM molecules with CQDs, and the results are shown in Fig. 2. The TGA thermogram (Fig. 2) shows that the complete decomposition of DHPM occurs at $300{ }^{\circ} \mathrm{C}$, as evidenced from the endothermic heat exchange in the DSC curve (not shown here). However, for CQD-DHPM, its decomposition occurs at a lower temperature. This suggests the conjugation between the inorganic CQDs and the organic DHPM, which triggers the decomposition of the organic part at a lower temperature by lowering the bond 

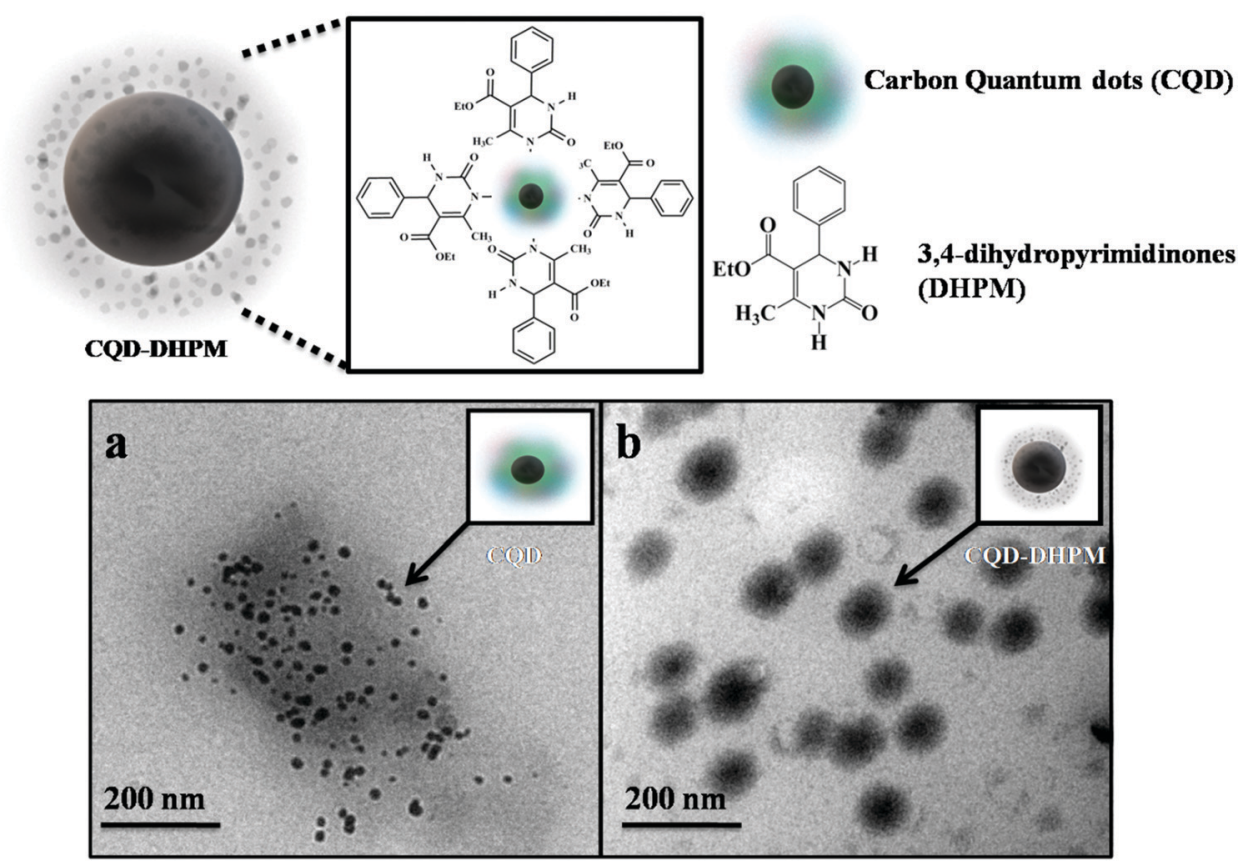

Fig. 1 HR-TEM analysis of (a) pure CQDs and (b) CQD-DHPM nanocomposite with a CQD : DHPM ratio of 1:2.

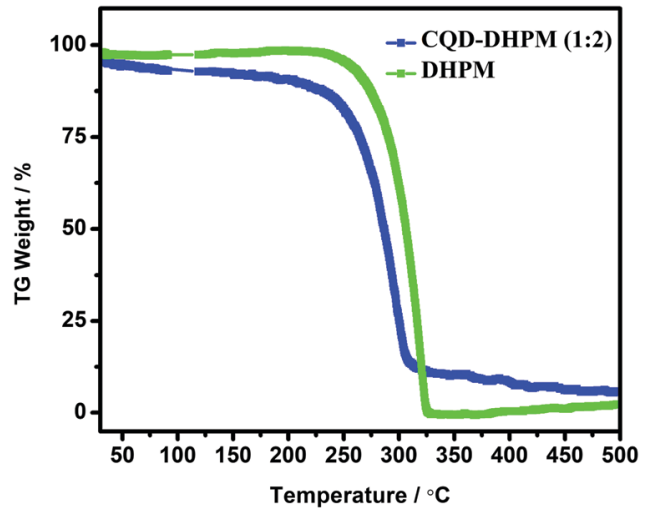

Fig. 2 TGA analysis of pure DHPM and CQD-DHPM nanocomposites with a CQD : DHPM ratio of $1: 2$

strength. It can be seen that there was a gradual weight loss even before that, which may be due to the slow burning of the surface-functionalization material (PSS) of CQDs. ${ }^{26}$ The decomposition was incomplete given that $\sim 15 \%$ of the sample was retained, which decayed slowly. This should be the inorganic part, which has a robust C-C structure. ${ }^{26}$ However, it should be noted that the phase transition temperature of the DHPM molecules did not change although the conjugation with CQDs strongly altered the thermodynamic properties of the DHPM molecules.

The conjugation between the DHPM molecules and CQDs was evidenced from the FTIR spectral analysis of the DHPM and CQD-DHPM samples. The detailed results are presented in the ESI. $\dagger$ Fig. 3 shows the FTIR spectra of the samples and the corresponding Tables S1-S6 (ESI $\dagger$ ) indicate the presence of $\mathrm{O}-\mathrm{H}$ stretching (broad, $\sim 3400 \quad \mathrm{~cm}^{-1}$ ), $\mathrm{N}-\mathrm{H}$ stretching (broad, $\left.3200 \mathrm{~cm}^{-1}\right), \mathrm{C}=\mathrm{O}$ stretching $\left(1750 \mathrm{~cm}^{-1}\right), \mathrm{C}-\mathrm{N}$ stretch $\left(\sim 1400 \mathrm{~cm}^{-1}\right)$, C-O-C stretching $\left(1226,1296 \mathrm{~cm}^{-1}\right)$ and C-N-C in amines $\left(1050 \mathrm{~cm}^{-1}\right)$. For the nanocomposites, the presence of $\mathrm{O}-\mathrm{H}$ stretching and systematic shift of the $\mathrm{C}-\mathrm{N}$ stretching towards a lower wavenumber are noticeable, which confirm the conjugation of CQDs and DHPM molecules and indicate the probable formation of $\mathrm{C}-\mathrm{N}$ bonds between the two components of the composites.

The pure DHPM and CQD-DHPM nanocomposites were also analyzed via ${ }^{1} \mathrm{H}$ NMR and the detailed spectral analysis of the samples is presented in the ESI $\dagger$ (Fig. S2-S4 and Tables S7-S11). The NMR spectra and the corresponding chemical shifts of the $1: 2$ ratio CQD-DHPM are shown in Fig. 4 and Table 1. The pure DHPM molecules exhibited NMR signals at $8.17 \mathrm{ppm}$ and $7.26 \mathrm{ppm}(\mathrm{m}, 3 \mathrm{H})$, corresponding to an aromatic and confirming the pyrimidine aldehyde, respectively. The two hydroamide signals were observed at $5.39 \mathrm{ppm}$ and $5.86 \mathrm{ppm}$. The presence of a peak at $3.7 \mathrm{ppm}\left(\mathrm{s}, 6 \mathrm{H}, 2 \mathrm{CH}_{3}\right)$ corresponded to the dimethylamino moiety. The peak at $2.3 \mathrm{ppm}$ $(\mathrm{s}, 3 \mathrm{H})$ shows the presence of an isolated methyl group and confirms the formation of DHPM. When the DHPM molecule was conjugated with CQDs, the NMR spectrum exhibited slight variations in peak positions, as shown in Fig. 4. The CQD-DHPM nanocomposites were observed to have a peak at $2.2 \mathrm{ppm}$ $(\mathrm{m}, 2 \mathrm{H})$ for the methyl on the linear chain, whereas the peaks from $3.00 \mathrm{ppm}$ to $4.00 \mathrm{ppm}$ are attributed to the isolated methyl group. The presence of a peak at $5.14 \mathrm{ppm}$ indicates the dimethylamino group. The aromatic protons in the composite were confirmed from the peak at $7.24 \mathrm{ppm}(\mathrm{m}, 3 \mathrm{H})$. It should be noted that signals appeared at around $9 \mathrm{ppm}$ to $7.32 \mathrm{ppm}$, which indicate a singlet consisting of a single H-proton. 


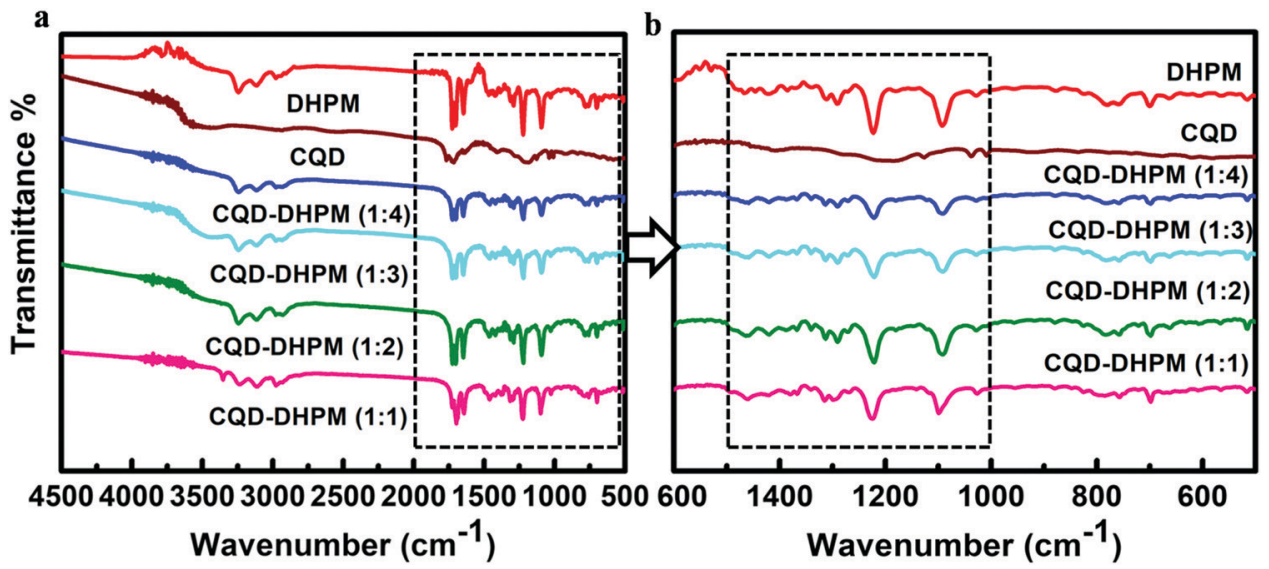

Fig. 3 (a) and (b) FT-IR spectroscopy analysis of DHPM, CQD and CQD-DHPM.

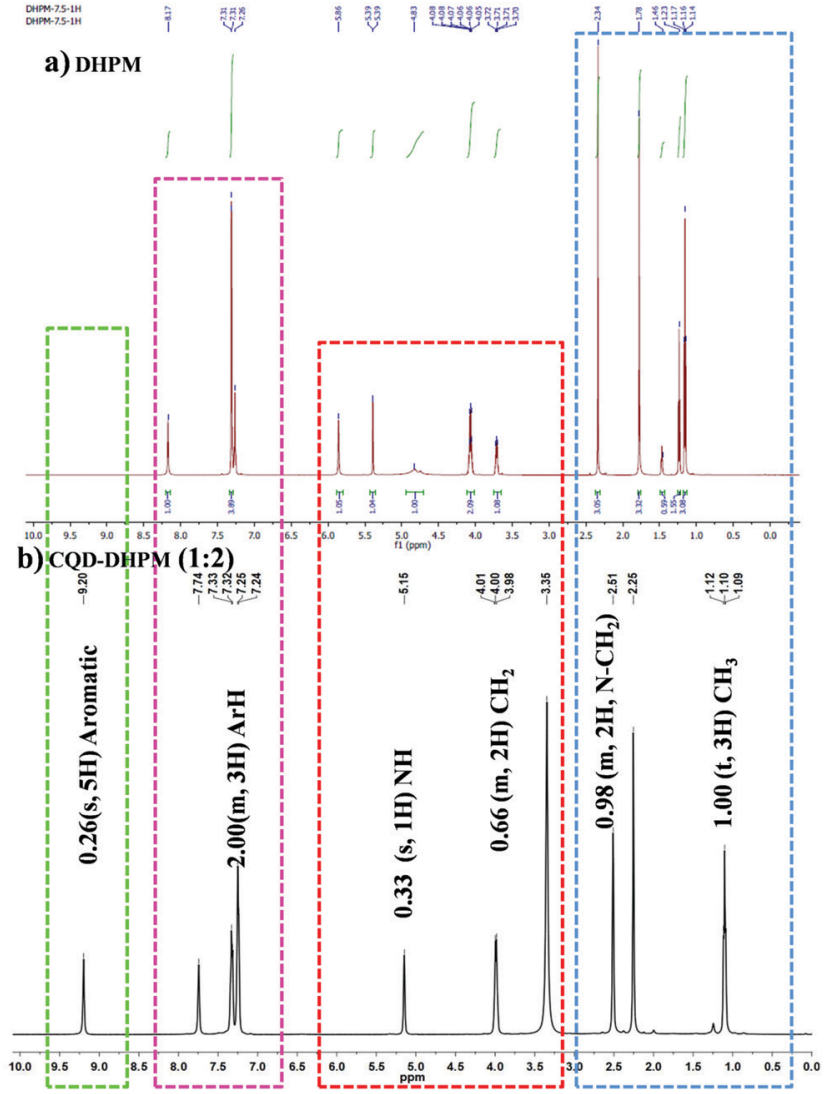

Fig. $4{ }^{1} \mathrm{H}$ NMR analysis of (a) pure DHPM and (b) CQD-DHPM nanocomposite with a CQD : DHPM ratio of $1: 2$

According to the above discussion, it is clear that DHPM and CQDs were conjugated. Several research groups previously reported that carbon nanomaterials including CQDs possess oxygen-containing functional groups on their surface and they can be conjugated with groups such as amines. ${ }^{15,27}$ However, in our case, the conjugation may have happened via the formation of covalent bonds between the amine groups of DHPM with the surface-functionalized group on CQDs. Therefore, we were interested to see whether this conjugation altered the optical properties of CQDs. It is essential that CQDs retain their fluorescence characteristics even within the nanocomposites so that they can be used as an efficient fluorophore. Accordingly, the prepared nanocomposite samples were analyzed via UV-Vis spectroscopy, fluorescence spectroscopy and fluorescence microscopy.

A prominent absorption peak at $284 \mathrm{~nm}$ was observed for 3,4-dihydropyrimidinones (DHPM) together with a small hump at around $221 \mathrm{~nm}$ (Fig. S5, ESI $\dagger$ ). Both the absorption peak and hump for DHPM appeared as a result of the $n \rightarrow \pi^{*}$ transition of $\mathrm{C}=\mathrm{O}$ and the presence of an $\mathrm{N}$ atom in the benzene ring of DHPM strengthened the peak at $284 \mathrm{~nm}$. Conversely, CQDs exhibited an absorption peak at $223 \mathrm{~nm}$ (Fig. S5 and Table S12, ESI $\dagger$ ). This absorption peak arises from the $\pi \rightarrow \pi^{*}$ transition of the $\mathrm{C}=\mathrm{C}$ bond present in CQDs. When DHPM was conjugated with CQDs, the peak at $284 \mathrm{~nm}$ peak was slightly red shifted $(\sim 2 / 3 \mathrm{~nm})$ in the CQD-DHPM nanocomposites. This small shift may be attributed to the strain in the heteroatom ring of the DHPM molecules in the composite. These variations are due to the strain in the heteroatom ring caused by the addition of functional chains to the ring and quantum dots.

The emission spectra of the aqueous CQD suspension were recorded at various excitation wavelengths. It can be seen in Fig. 5 that with an increase in the excitation wavelength from $310 \mathrm{~nm}$ to $410 \mathrm{~nm}$, the emission peak slowly shifted from $440 \mathrm{~nm}$ to $490 \mathrm{~nm}$ with varying intensities. However, the strongest emission peak of CQDs appeared at $442 \mathrm{~nm}$ for the excitation wavelength of $360 \mathrm{~nm}$. These results are compatible with our previous reports. ${ }^{15}$ The emission spectra of different CQD-DHPM nanocomposites in aqueous suspension are shown in Fig. 5. These spectra are similar to that of CQDs only. This evidence demonstrated that the optical properties of CQDS remained almost unaltered in the nanocomposites given that DHPM has no fluorescence property. The only difference observed for the CQD-DHPM nanocomposites was the change in the strongest emission peak position and the excitation wavelength for the highest emission peak. For the different CQD-DHPM composites, both peaks were red shifted by $10 \mathrm{~nm}$. 
Table 1 Chemical shift values of pure DHPM (PTA-Jeffamine $\left.{ }^{\circledR} \mathrm{pH}-7.5\right)$-catalyzed reaction and CQD-DHPM (1:2 ratio)

\begin{tabular}{|c|c|c|c|c|}
\hline S. no. & DHPM peak (ppm) & Chemical shift $(J)$ & CQD-DHPM (1:2) (ppm) & Chemical shift $(J)$ \\
\hline 1 & $1.14-1.17$ & $3.08(\mathrm{t}, 3 \mathrm{H}) \mathrm{CH}_{3}$ & $1.09-1.12$ & $1.00(\mathrm{t}, 3 \mathrm{H}) \mathrm{CH}_{3}$ \\
\hline 2 & 1.23 & $1.55(\mathrm{~m}, 6 \mathrm{H})$ & $2.25-2.51$ & $0.98\left(\mathrm{~m}, 2 \mathrm{H}, \mathrm{N}-\mathrm{CH}_{2}\right)$ \\
\hline 3 & 1.46 & $0.59(\mathrm{~s}, 3 \mathrm{H}) \mathrm{CH}_{3}$ & $3.35-4.01$ & $0.66(\mathrm{~m}, 2 \mathrm{H}) \mathrm{CH}_{2}$ \\
\hline 4 & 1.78 & $3.32 \mathrm{~m}, 2 \mathrm{H}, \mathrm{CH}_{2}$ & 5.14 & $0.33(\mathrm{~s}, 1 \mathrm{H}) \mathrm{NH}$ \\
\hline 5 & 2.34 & $3.05(\mathrm{~s}, 3 \mathrm{H}) \mathrm{CH}_{3}$ & $7.24-7.74$ & $2.00(\mathrm{~m}, 3 \mathrm{H}) \mathrm{ArH}$ \\
\hline 6 & $3.70-3.72$ & $1.08\left(\mathrm{~m}, 2 \mathrm{H}, \mathrm{N}-\mathrm{CH}_{2}\right)$ & 9.20 & $0.26(\mathrm{~s}, 5 \mathrm{H})$ aromatic \\
\hline 7 & $4.05-4.08$ & $2.09(\mathrm{~m}, 2 \mathrm{H}) \mathrm{CH}_{2}$ ethyl & - & - \\
\hline 8 & 4.83 & $1.00(\mathrm{~m}, 1 \mathrm{H}, \mathrm{C} 4-\mathrm{H})$ & - & - \\
\hline 9 & 5.39 & $1.05(\mathrm{~s}, 1 \mathrm{H}) \mathrm{NH}$ & - & - \\
\hline 10 & 5.86 & $1.04(\mathrm{~s}, 1 \mathrm{H}) \mathrm{NH}$ & - & - \\
\hline 11 & $7.26-7.31$ & $3.89(\mathrm{~m}, 3 \mathrm{H}) \mathrm{ArH}$ & - & - \\
\hline 12 & 8.17 & $1.00(\mathrm{~s}, 5 \mathrm{H})$ Aromatic & - & - \\
\hline
\end{tabular}
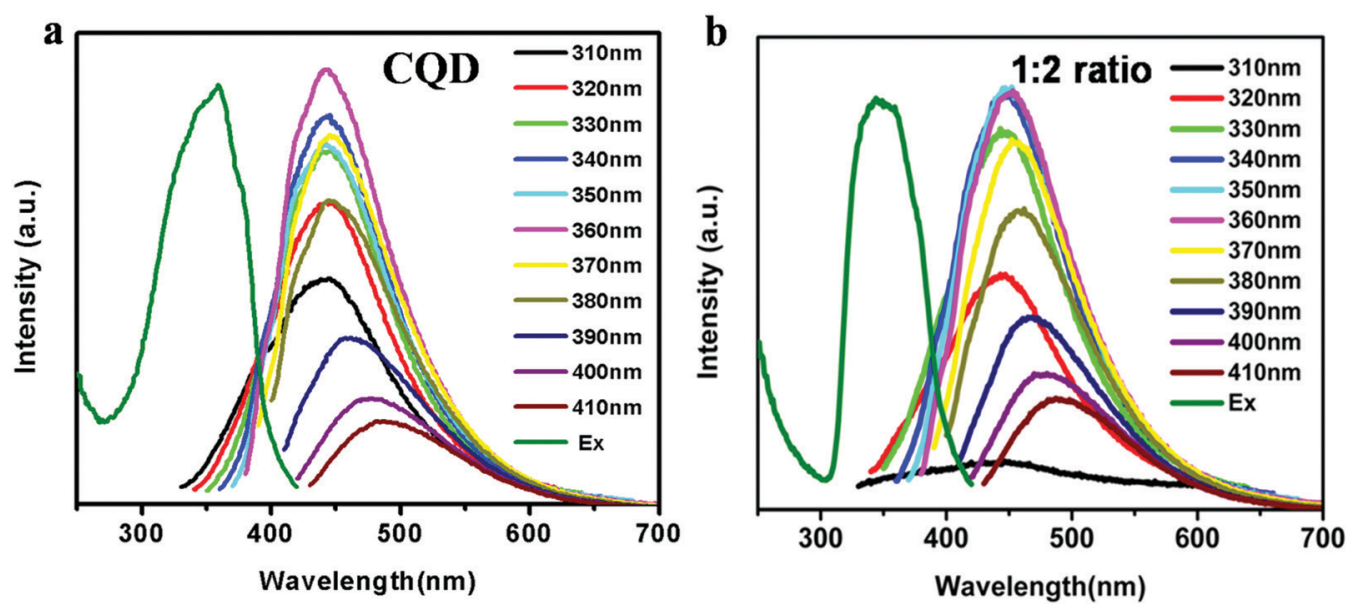

Fig. 5 Photoluminescence spectra of (a) CQD and (b) CQD-DHPM nanocomposite with a CQD:DHPM ratio of 1:2 under different excitation and emission wavelengths $(310-410 \mathrm{~nm})$. With a change in excitation wavelength, the emission peak wavelengths also changed.

The excitation-dependent emission feature of CQDs enables the use of the nanocomposites for multicolor labeling of cells via fluorescence imaging.

The crystals of dihydropyrimidinones and the nanocomposites were visible under a microscope. Interestingly, the fluorescence microscopy images of the CQD-DHPM nanocomposites had different fluorescent structures when the proportion of dihydropyrimidinones to CQD was varied. Fig. 6 shows the different structures of the CQD-DHPM conjugates with a CQD:DHPM ratio of $1: 1,1: 2,1: 3$ and $1: 4$, respectively. Although the exact reason for the formation of these different structures has not been explored, probably with an increase in the content of DHPM molecules, the availability of growth sites on the surface of CQDs guided the directionality of crystal formation in different shapes. Thus, the formation of the nanocomposites and their structural properties were confirmed by the above characterization techniques.

In recent years, the interest in dihydropyrimidinones and their analogues as anti-cancer drugs has significantly increased. In contrast to other anti-cancer drugs, which perturb mitosis by binding to the protein tubulin-like natural taxanes, vinca alkaloids and epothilones, monastrols (DHPM derivatives) specifically affect cell division by a new mechanism. Kinesin Eg5, a spindle motor protein, is an attractive therapeutic target to prevent cell cycles by mitosis. Monastrol drugs inhibit kinesin Eg5 to form bipolar spindles by polar migration of centrosomes, resulting in the formation of monoastral spindles, and thus restricting mitosis. ${ }^{8,28,29}$ For decades, several researchers synthesized DHPM with modifications in its structure to enhance its activity against microbial pathogens and cancer cells of interest.

In this study, we used DHPM (dihydropyrimidinones) alone, CQDs alone and CQD-DHPM (carbon quantum dot-DHPM) nanocomposites with four different CQD : DHPM ratios of $1: 1$, $1: 2,1: 3$, and $1: 4$ to evaluate their cytotoxic activity against the A549 cell line. Analyzing the percentage viability and percentage growth inhibition for the DHPM compounds, we observed a dose-dependent cytotoxicity for all the drugs against the A549 cell line. The percentage viability decreased proportionally with an increase in the drug concentration, as shown in Fig. 7a. After $24 \mathrm{~h}$ of treatment, the viability of the A549 cells was reduced to a greater extent at higher concentrations (i.e., above $200 \mu \mathrm{M})$ while using the CQD-DHPM nanocomposites $(1: 1,1: 2,1: 3$, and $1: 4)$. To establish the optimal treatment concentration for DHPM and its composites, the $\mathrm{IC}_{50}$ values were calculated and compared, as shown in Table 2 . The half maximal inhibitory concentration of the DHPM compounds against A549 cells was calculated, with an $R^{2}$ value of 0.99 . 


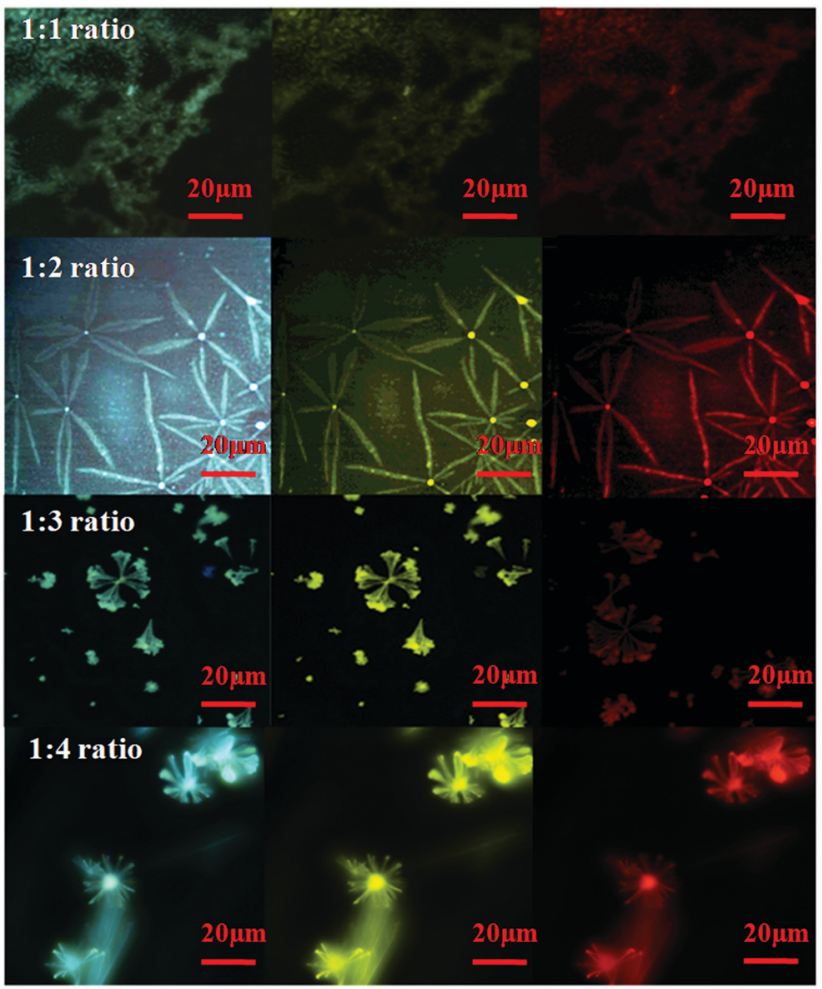

Fig. 6 Fluorescence microscopy images of CQD-DHPM nanocomposites with CQD : DHPM ratios of $1: 1,1: 2,1: 3$, and $1: 4$ under a blue, green and red filter.

We used healthy PBMCs to evaluate the cytotoxicity of the compounds against healthy host cells. There are earlier reports of anti-tumor monastrols where the cytotoxicity studies to normal cells were not reported. ${ }^{30}$ The toxicity of our synthesized DHPM compounds against normal cells (PBMCs) remained low even at the half maximal inhibitory concentration $(<20 \%)$, as shown in Fig. $7 \mathrm{~b}$. In the research work published by Venugopal et al., the DHPM derivatives exhibited up to $20 \%$ growth inhibition at $50 \mu \mathrm{g} \mathrm{mL}{ }^{-1}$, i.e., $\sim 50 \mathrm{mM}^{31}$ The lithium-acetate-mediated Biginelli compounds required more than $100 \mu \mathrm{M}$ to exert $50 \%$ cytotoxic activity against the A549 cell line. In the current study, the viability of PBMCs was found to remain greater than $60 \%$ even after $72 \mathrm{~h}$ of CQDDHPM treatment, as shown in Fig. $7 \mathrm{~b}$ (note that the maximum concentration used for all the drugs was $500 \mu \mathrm{M})$. We confirmed that the CQD-DHPM analogues are non-toxic to PBMCs by comparing their activity to that with A549 cells (Table 3). The percentage growth inhibition of the drugs against both the A549 cell line and PBMCs was compared at a concentration of $100 \mu \mathrm{M}$, as shown in Table 3. The higher percentage of growth inhibition of cancer cells at lower dosages and much shorter incubation time compared to the normal cells proved that the drugs exhibit inhibition specificity towards A549 cancer cells.

Comparing the DHPM derivatives treated against the breast cancer cell line model by Guido et al. using the MCF7 and MDA-MB-231 cell lines, ${ }^{30}$ the novel synthesized DHPM (a)

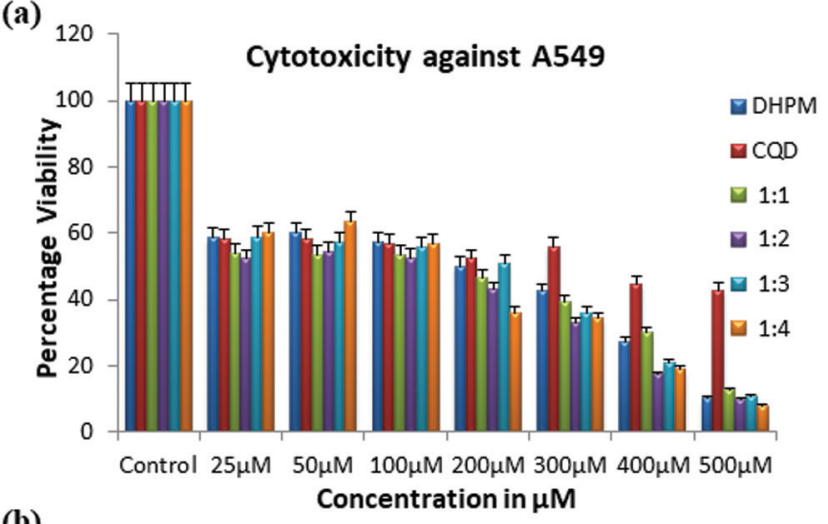

(b)

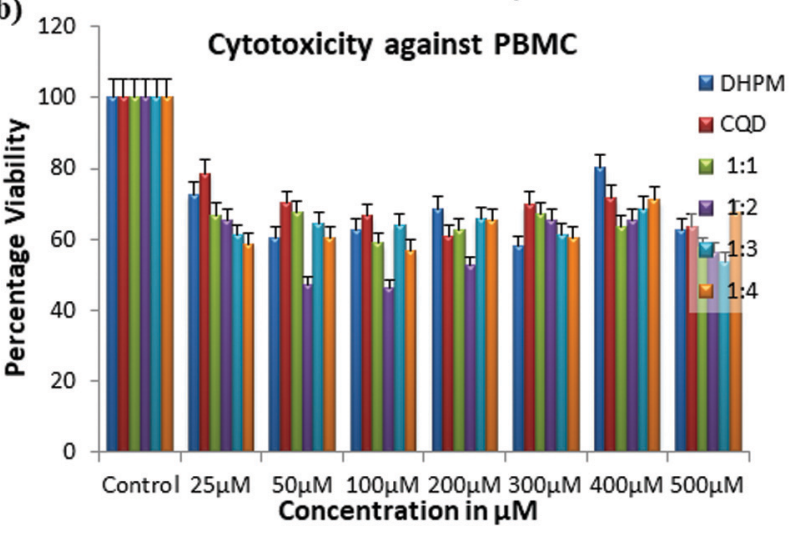

Fig. 7 Cytotoxic effect of DHPM and CQD-DHPM against A549 and PBMCs. Dose-dependent cytotoxicity of (a) DHPM, CQD and CQD-DHPM nanocomposites against A549 cell line after $24 \mathrm{~h}$ treatment and (b) CQDDHPM nanocomposites against PBMCs after $72 \mathrm{~h}$ treatment. Errorbars with standard deviation has been provided for each cases.

Table 2 Levels of cytotoxicity exhibited by the DHPM composites against A549 (non-small cell lung carcinoma) $24 \mathrm{~h}$ treatment

\begin{tabular}{llc}
\hline S. no. & DHPM composites & Cytotoxicity $\left(\mathrm{IC}_{50}\right.$ in $\left.\mu \mathrm{M}\right)$ \\
\hline 1 & DHPM (dihydropyrimidinones) & 202.6 \\
2 & CQD (carbon quantum dots) & $>350$ \\
3 & CQD-DHPM nanocomposite $(1: 1)$ & 160.4 \\
4 & CQD-DHPM nanocomposite $(1: 2)$ & 128.5 \\
5 & CQD-DHPM nanocomposite $(1: 3)$ & 232.5 \\
6 & CQD-DHPM nanocomposite $(1: 4)$ & 181.6
\end{tabular}

Table 3 Comparison of percentage growth inhibition of DHPM composites against A549 and PBMCs at $100 \mu \mathrm{M}$ concentration. A549 - non-small cell lung carcinoma (NSCLC) and PBMCs - peripheral blood mononuclear cells

Percentage (\%) of growth inhibition

S. no. DHPM composites A549 (24 h) PBMCs (72 h)

$\begin{array}{lll}\text { DHPM (dihydropyrimidinones) } & 42.6 & 26.42 \\ \text { CQD (carbon quantum dots) } & 43.4 & 19.17 \\ \text { CQD-DHPM nanocomposite }(1: 1) & 46.5 & 32.79 \\ \text { CQD-DHPM nanocomposite }(1: 2) & 47.5 & 20.94 \\ \text { CQD-DHPM nanocomposite }(1: 3) & 44.3 & 35.9 \\ \text { CQD-DHPM nano composite }(1: 4) & 43.4 & 43.13\end{array}$



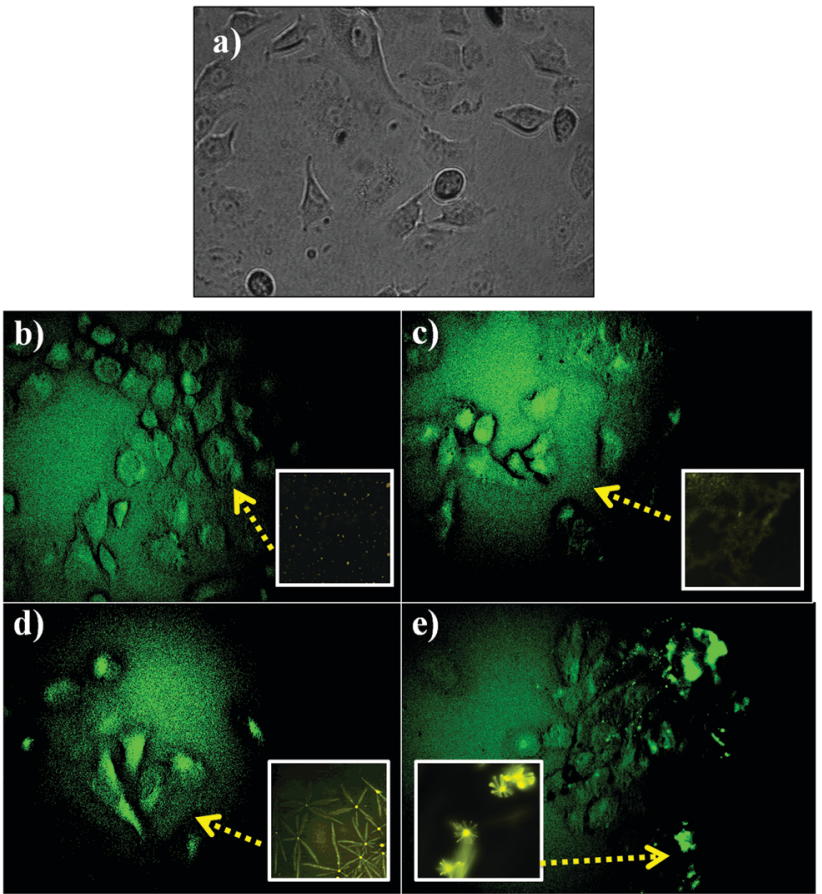

Fig. 8 Fluorescence imaging showing the entry of CQD and CQD-DHPM in the target cells. In vitro examination of fluorescence microscopic analysis under excitation wavelength of $380 \mathrm{~nm}$ and bright field of (a) A549 untreated cells, (b) CQD $(350 \mu \mathrm{M})$, (c) CQD-DHPM conjugates with a CQD : DHPM ratio of ratio of $1: 1(160.4 \mu \mathrm{M}),(\mathrm{d}) 1: 2(128.5 \mu \mathrm{M})$, and (e) $1: 4$ $(181.6 \mu \mathrm{M})$ (inset: fluorescent microscopic structures).

molecule and CQD-DHPM nanocomposites in our study were proven to show a significant decrease in cell viability gradually at all concentrations. The CQD-DHPM nanocomposites $(1: 2)$ had the lowest half maximal inhibitory concentration compared to other combinations. This behavior may be attributed to the number of accessible DHPM molecules in the combination together with the structural advantages of the CQDs. However, CQDs alone also showed inhibitory activity at higher concentrations against A549 cells. $^{22}$ In the research work published by Guido et al., DHPM and its derivatives were used at concentrations of up to $1 \mathrm{mM}^{6,30}$ The DHPM derivatives exhibited over $80 \%$ cell growth inhibition with $\mathrm{IC}_{50}$ of around 6 to $35 \mu \mathrm{M} .{ }^{31}$ It has been previously shown that monastrol mimic Biginelli DHPM derivatives exhibit cytotoxicity against HepG2 with half maximal inhibitory concentration of $120.62 \mu \mathrm{g} \mathrm{mL}$ and weak toxicity towards HeLa cell lines with $\mathrm{IC}_{50}$ of $200 \mu \mathrm{g} \mathrm{mL}{ }^{-1}{ }^{6}$

The in vitro examination of DHPM in combination with CQDs was viewed via fluorescence microscopy for tracking the location of the nanocomposites inside the target cells. The microscopic image revealed the entry of the CQD-DHPM nanocomposites in the cells exciting at $450 \mathrm{~nm}$, as shown in Fig. 8. The PL analysis (Fig. $3 \mathrm{~b}$ ) also supports the excitation of the composites at the same wavelength.

This phenomenon of successful fluorescence property of the CQD-DHPM composites is consistent with the report by M. J. Molaei et al. ${ }^{32}$ that carbon-based materials with a particle size larger than $70 \mathrm{~nm}$ can also emit fluorescence and be used for bio-imaging applications, although particles less than $10 \mathrm{~nm}$ are commonly used for bioimaging applications. ${ }^{32}$ Further studies need to be done to elucidate the molecular pathways in the NSCLC cancer cell line death induced by DHPM and its nanocomposites.

\section{Conclusion}

We prepared nanocomposites of CQDs and DHPM molecules and confirmed their formation using different characterization techniques. The newly synthesized CQD-DHPM nanocomposites in our study were found to exhibit moderate activity against the A549 cancer cell line at a low concentration. The CQD-DHPM composite with a CQD:DHPM ratio of $1: 2$ exhibited robust cytotoxicity against NSCLC compared to the other ratios and DHPM alone. These composites were more specific to cancer cells and exhibited a very low toxic effect on normal cells (PBMCs). Due to their superior fluorescence properties, these composites show bioimaging capability for excitation at $450 \mathrm{~nm}$. Thus, a multifunctional nanocomposite was developed in this study, which shows decent anti-cancer activity against the NSCLC cell line and can be used as a fluorophore.

\section{Conflicts of interest}

There are no conflicts to declare.

\section{Acknowledgements}

The authors acknowledge no conflict of interests. This work is financially supported by Science and Engineering Research Board, Department of Science and Technology, Govt. of India (KM \& RRB, Project No. - EMR/2016/005327). ST, HPM, SJ and KM also would like to thank PSG Institutions Management for lab facilities and infrastructural access. We would also acknowledge the technical discussions with Dr Thiagarajan, an ex-faculty of CMMT.

\section{References}

1 L. Yang, Y. Zeng, H. Wu, C. Zhou and L. Tao, J. Mater. Chem. $B, 2020,8,1383-1388$.

2 A. M. Vijesh, A. M. Isloor, S. K. Peethambar, K. N. Shivananda, T. Arulmoli and N. A. Isloor, Eur. J. Med. Chem., 2011, 46, 5591-5597.

3 F. Manetti, A. Santucci, G. A. Locatelli, G. Maga, A. Spreafico, T. Serchi, M. Orlandini, G. Bernardini, N. P. Caradonna, A. Spallarossa, C. Brullo, S. Schenone, O. Bruno, A. Ranise, F. Bondavalli, O. Hoffmann, M. Bologna, A. Angelucci and M. Botta, J. Med. Chem., 2007, 50, 5579-5588.

4 C. Mugnaini, M. Alongi, A. Togninelli, H. Gevariya, A. Brizzi, F. Manetti, C. Bernardini, L. Angeli, A. Tafi, L. Bellucci, 
F. Corelli, S. Massa, G. Maga, A. Samuele, M. Facchini, I. Clotet-Codina, M. Armand-Ugón, J. A. Esté and M. Botta, J. Med. Chem., 2007, 50, 6580-6595.

5 N. Rioux and A. Castonguay, Carcinogenesis, 1998, 19, 1393-1400.

6 U. Soumyanarayanan, V. G. Bhat, S. S. Kar and J. A. Mathew, Org. Med. Chem. Lett., 2012, 2, 23.

7 S. Terracciano, M. G. Chini, M. C. Vaccaro, M. Strocchia, A. Foglia, A. Vassallo, C. Saturnino, R. Riccio, G. Bifulco and I. Bruno, Chem. Commun., 2016, 52, 12857-12860.

8 G. M. Chin and R. Herbst, Mol. Cancer Ther., 2006, 5, 2580.

9 L. H. S. Matos, F. T. Masson, L. A. Simeoni and M. Homemde-Mello, Eur. J. Med. Chem., 2018, 143, 1779-1789.

10 F. A. F. Ragab, S. M. Abou-Seri, S. A. Abdel-Aziz, A. M. Alfayomy and M. Aboelmagd, Eur. J. Med. Chem., 2017, 138, 140-151.

11 C. Zappa and S. A. Mousa, Transl. Lung Cancer Res., 2016, 5, 288-300.

12 M. Infante, T. Berghmans, M. A. Heuvelmans, G. Hillerdal and M. Oudkerk, Eur. Respir. J., 2013, 42, 1706.

13 B. S. Holla, B. S. Rao, B. K. Sarojini and P. M. Akberali, Eur. J. Med. Chem., 2004, 39, 777-783.

14 N. S. White and R. J. Errington, Adv. Drug Delivery Rev., 2005, 57, 17-42.

15 L. Bhattacharjee, K. Mohanta, K. Pal, A. L. Koner and R. R. Bhattacharjee, J. Mater. Chem. A, 2016, 4, 2246-2251.

16 A. L. Antaris, H. Chen, S. Diao, Z. Ma, Z. Zhang, S. Zhu, J. Wang, A. X. Lozano, Q. Fan, L. Chew, M. Zhu, K. Cheng, X. Hong, H. Dai and Z. Cheng, Nat. Commun., 2017, 8, 15269.

17 L. Bhattacharjee, R. Manoharan, K. Mohanta and R. R. Bhattacharjee, J. Mater. Chem. A, 2015, 3, 1580-1586.
18 H. Guo, B. You, S. Zhao, Y. Wang, G. Sun, Y. Bai and L. Shi, RSC Adv., 2018, 8, 24002-24012.

19 A.-M. Alam, B.-Y. Park, Z. K. Ghouri, M. Park and H.-Y. Kim, Green Chem., 2015, 17, 3791-3797.

20 Y. Song, S. Zhu and B. Yang, RSC Adv., 2014, 4, 27184-27200.

21 Y. Wang and A. Hu, J. Mater. Chem. C, 2014, 2, 6921-6939.

22 K. S. Prasad, G. Shruthi and C. Shivamallu, Inorg. Chem. Commun., 2019, 101, 11-15.

23 Q. Qu, A. Zhu, X. Shao, G. Shi and Y. Tian, Chem. Commun., 2012, 48, 5473-5475.

24 T. Suppan, H. P. Mahendran, S. Jeyaraj, K. Mohanta and R. R. Bhattacharjee, Appl. Catal., A, 2020, 603, 117734.

25 F. Vitório, T. M. Pereira, R. N. Castro, G. P. Guedes, C. S. Graebin and A. E. Kümmerle, New J. Chem., 2015, 39, 2323-2332.

26 T. Warsi, L. Bhattacharjee, S. Thangamani, S. K. Jat, K. Mohanta, R. R. Bhattacharjee, R. Ramaswamy, C. Manikyamba and T. V. Rao, Diamond Relat. Mater., 2020, 103, 107701.

27 L. Li and T. Dong, J. Mater. Chem. C, 2018, 6, 7944-7970.

28 D. Dallinger and C. O. Kappe, Nat. Protoc., 2007, 2, 317-321.

29 A. S. Mostafa and K. B. Selim, Eur. J. Med. Chem., 2018, 156, 304-315.

30 B. C. Guido, L. M. Ramos, D. O. Nolasco, C. C. Nobrega, B. Y. G. Andrade, A. Pic-Taylor, B. A. D. Neto and J. R. Corrêa, BMC Cancer, 2015, 15, 283.

31 K. N. Venugopala, R. Govender, M. A. Khedr, R. Venugopala, B. E. Aldhubiab, S. Harsha and B. Odhav, Drug Des., Dev. Ther., 2015, 9, 911.

32 M. J. Molaei, RSC Adv., 2019, 9, 6460-6481. 